\title{
Incidence and seroprevalence of tularaemia in Finland, 1995 to 2013: regional epidemics with cyclic pattern
}

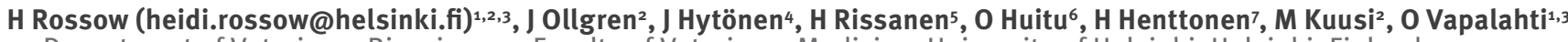

1. Department of Veterinary Biosciences, Faculty of Veterinary Medicine, University of Helsinki, Helsinki, Finland

2. Infectious Disease Control Unit, Department of Infectious Diseases, National Institute for Health and Welfare, Helsinki, Finland

3. Virology, University of Helsinki and Helsinki University Hospital, Helsinki, Finland

4. Department of Medical Microbiology and Immunology, University of Turku, Turku, Finland

5. Health Monitoring Unit, Department of Health, National Institute for Health and Welfare, Helsinki, Finland

6. Suonenjoki Unit, Natural Resources Institute, Suonenjoki, Finland

7. Vantaa Unit, Natural Resources Institute, Vantaa, Finland

We studied the incidence of reported tularaemia by year and region and the prevalence of antibodies against Francisella tularensis in the adult general population in Finland. Moreover, we assessed the correlation between vole population cycles and human tularaemia outbreaks. The seroprevalence study made use of serum samples from a nationwide populationbased health survey (Health 2000). The samples of 1,045 randomly selected persons, representative for the Finnish population in each region, were screened with an enzyme-linked immunosorbent assay (ELISA) for the presence of IgG antibodies against $F$. tularensis, and positive results were further confirmed by immunoblotting. A serological response to $F$. tularensis was found in $2 \%$ ( $95 \%$ confidence interval: $1.1-3.5$ ) of the population. Incidence and seroprevalence were highest in the same areas, and vole population peaks clearly preceded tularaemia outbreaks one year later.

\section{Introduction}

Tularaemia is a zoonotic disease caused by the intracellular bacterium Francisella tularensis $[1,2]$. The disease is caused primarily by two of four subspecies: the highly virulent type A strain F. tularensis subsp. tularensis which is almost completely restricted to North America, and the less virulent type B strain F. tularensis subsp. holarctica, which occurs in many regions of the northern hemisphere, including Finland $[1,2]$.

Recurrent outbreaks with hundreds of cases are reported in Finland and Sweden [3,4]; in other European countries, the disease is rare, but many countries report sporadic outbreaks [5-7]. Geographically, the disease shows a focal distribution [8]. The pathogen is most likely to persist in the local environment but seems to cause epidemics only when the ecological conditions are favourable for an active infectious cycle [9]. Thus, appropriate reservoirs, amplifiers, vectors and suitable climatic conditions are needed for an outbreak of human tularaemia [9]. Tularaemia is typically associated with outdoor activities, and farmers and hunters are at particular risk for infection [3-7,10]. In Finland and Sweden, the disease is typically mosquito-transmitted and most cases are reported during August and September in connection with the occurrence of late summer mosquito species [3,4], whereas in Norway, the disease occurs in autumn and winter and the most common source is drinking water contaminated by rodents [11]. Outbreaks in Norway and Kosovo* have been linked to high rodent densities [11-14].

Airborne outbreaks, mainly associated with activities that can generate aerosols, such as farming, gardening or hunting, occur occasionally in all endemic countries and are very local $[5-7,15]$.

Human tularaemia typically starts with non-specific influenza-like symptoms [16]. Other clinical manifestations depend mainly on the route of transmission, and the disease severity depends on the infecting subspecies and strain $[1,16]$. After infection, antibodies against $F$. tularensis rise slowly but are detectable for several years [17]. Here we report a study conducted in Finland, aiming to determine the incidence of tularaemia and the prevalence of $F$. tularensis antibodies in the population in 2000 and 2001, to compare the seroprevalence rates with the number of reported cases for the period 1995 to 2013, and to assess for the same period the role of vole population cycles in the temporal and spatial pattern of human tularaemia outbreaks.

\section{Methods}

National laboratory-based surveillance

The Finnish national healthcare system is organised in 20 geographically and administratively distinct 
healthcare districts. Laboratory-confirmed tularaemia has been a notifiable disease by the diagnosing laboratory since 1995, and clinical microbiology laboratories report cases directly to the National Infectious Disease Register (NIDR) which is maintained by the National Institute for Health and Welfare (THL). Diagnostic criteria for reporting include (i) isolation of $F$. tularensis in a clinical specimen, (ii) a more than four-fold rise in serum antibody titre or a single antibody titre of $>160$ when using an agglutination assay or (iii) the presence of specific IgM and IgG antibodies in the serum when an enzyme-linked immunosorbent assay (ELISA) is used. With each notification, the following information is given: date and type of specimen, date of birth, sex, place of treatment and place of residence.

\section{Human serum samples and background health information}

Serum samples were collected in a multidisciplinary epidemiological health survey, the Health 2000 Study, carried out in the years 2000-01 in Finland [18]. Detailed study methods have been described elsewhere [18]. Sera from adults were collected in 80 different areas covering most of the country. For the current study, serum samples from 1,045 randomly selected persons were included. For geographical coverage, all 20 healthcare districts were represented with 50 samples, except for Central Ostrobothnia where only 45 samples were available and the capital district of Helsinki and Uusimaa, which was represented with 100 samples, reflecting a union of two formerly separate districts. An extensive health interview and health examination had been done for all participants in the original study. In this study, we especially focused our analyses on common symptoms and medical conditions, living environment, occupation, leisure activities, physical condition, smoking and alcohol use and demographic factors. The Health 2000 Survey was approved by the Ethical Committee for Research in Epidemiology and Public Health at the Hospital District of Helsinki and Uusimaa.

Sera from seven patients who had laboratory-confirmed tularaemia (diagnosed at the Department of Medical Microbiology and Immunology, University of Turku) one to 16 years before serum collection, were used as positive control sera.

\section{Serological testing}

\section{ELISA}

All serum samples were screened for $F$. tularensis antibodies by ELISA as previously described [17], with whole bacterium lysate prepared from $F$. tularensis live vaccine strain (LVS) as the antigen. Serum samples were tested at a dilution of 1:100. Absorbances (OD405) were measured with BEP III apparatus (Siemens Healthcare Diagnostics Products $\mathrm{GmbH}$, Erlangen, Germany). Results were expressed as arbitrary enzyme-immunosorbent units (EIU) on the scale from zero to 100 units. Conventional receiver operating characteristic ROC) analysis to determine the cut-off of the ELISA could not be performed because the true tularaemia antibody status (defined by a gold standard) of our samples or for the ELISA test in general was not known. This is why a confirmatory Western blot was employed.

Western blot

Western blotting was conducted as earlier described [19]. Positive sera showed a typical lipopolysaccharide (LPS) band pattern at a dilution of 1:100. Samples were screened from the highest EIU (83.7) in ELISA down to EIU 26.8 (including 55 serosurvey samples and seven positive control samples). The lowest ELISA EIU value that was still positive in Western Blot was 28.5. The following 10 samples were WB negative and screening was stopped due to low EIU values of the remaining samples. Only samples positive in both EIA and WB were considered positive.

Vole data

Data on small mammals were collected biannually in ca 30 locations around the country by the Natural Resources Institute, as described by previously [20]. The trapped mammals were predominantly voles, which dominate the rodent and other small mammal fauna in Finland $[20,21]$. Only vole populations show cyclic fluctuations. In addition, three wild murine (i.e. non-vole rodent) species inhabit Finland, but they are restricted to the southern half of the country, and usually occur at low densities with seasonal, but not cyclic dynamics. As such, the national monitoring programme of vole populations was planned to produce comprehensive data on the spatiotemporal dynamics of vole population fluctuations around the whole country. By and large, vole populations in Finland fluctuate pronouncedly in cycles of three to four years [20]. For the purposes of this study, the vole population data (density indices; voles per 100 trap nights) were qualitatively classified into three distinct cyclic phases, each corresponding to a year: population peak years, population decline years and population increase years.

\section{Statistical analyses}

Serological survey

Statistical analyses were performed using IBM SPSS Statistics version 22 and the programme $R$ maptools package was used to construct the maps. Our dataset was a subsample selected from the Health 2000 survey main study by stratified simple sampling of size 50 samples per hospital district, and the original sampling weights were reweighted to match the population size of a given hospital district at year 2000. Of the very comprehensive background information, we especially focused our analyses on common symptoms and medical conditions, living environment, occupation, leisure activities, physical condition, smoking and alcohol use and demographic factors. Univariate chi-square tests were computed taking into account the sampling design, its strata and clusters and the sampling weights for the test of independence of the categorical 
Incidence rates of laboratory-confirmed tularaemia infections, Finland, 1995-2013

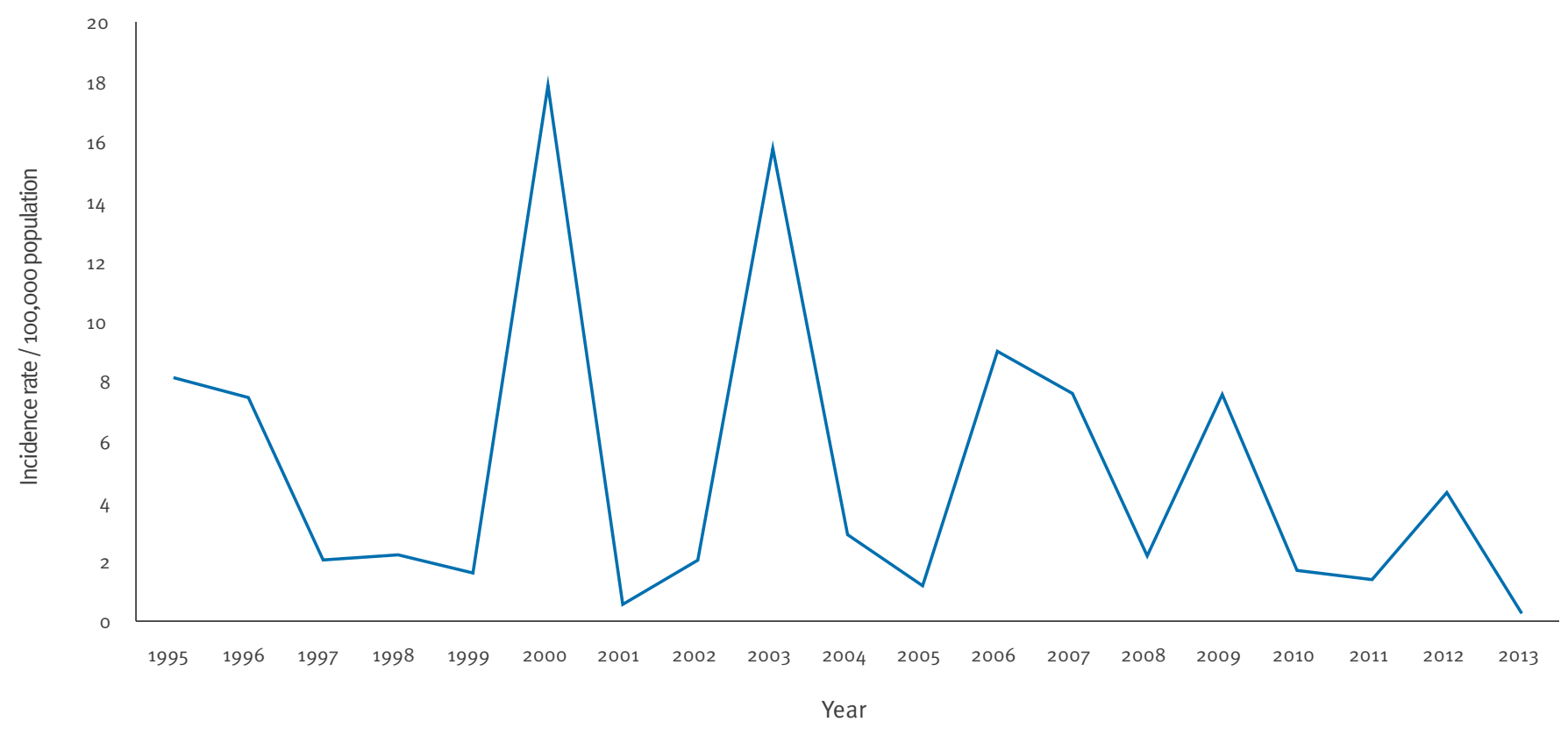

variables. The population sizes and prevalences were estimated accordingly, taking into account sampling design. Logistic regression was used to model the relationship between seroprevalence odds and explanatory variables. The incidence ratio of notified/total tularaemia cases was calculated assuming that the population at risk and the prevalence pool were stationary. Applying a formula for a time stationary situation, the (sero)prevalence odds of tularaemia $p /(1-p)$, the mean total incidence I and the mean duration of the seroprevalence $D$ are related as $p /(1-p)=I \times D$, with $D$ equal to the estimated average residual life time after the mean age of acquiring tularaemia.

Vole and surveillance data analysis

The association between tularaemia outbreaks and phase of vole cycle was analysed with Poisson regression. Poisson model calculations were done by hospital district. The effect of vole cyclic phase factor was assumed independent of the year. Possible overdispersion was corrected by Pearson chi-squared scale parameter method, and possible autocorrelations of person residuals from the model were checked by autocorrelation plots (ACF plots).

\section{Results}

\section{National laboratory-based surveillance}

From 1995 to 2013, 5,086 notifications of laboratoryconfirmed tularaemia cases were reported to the NIDR. The annual number of notified cases ranged from 14 to 926 . The average annual incidence was $5.1 / 100,000$ population and the highest incidence (18/100,000 population) was recorded during the year of the major epidemic in 2000 (Figure 1).
Rates were typically highest in the health districts of Northern and Southern Ostrobothnia and Central Finland. The mean age of the cases was 45 years (range: $0-93$ years) and 55\% were male. The annual variation in reported cases in the three healthcare districts with particularly high incidence is shown in Figure 2. Typically, epidemics occurred in different districts every third or fourth year.

Epidemics were strongly seasonal, with the majority of cases diagnosed during summer and early autumn (Figure 3).

Figure 4 shows the incidence rates by healthcare district in 1995-2000, five to six years before sampling for the seroprevalence study.

\section{Human seroprevalence study}

Our study sampling of 1,045 persons comprised $46 \%$ men and $54 \%$ women. Their mean age was 53 years (range: 30-92 years) and for geographical coverage, they represented all 20 healthcare districts. We found 16 positive samples (1.5\%), which after adjustment with survey weights gave an estimated overall $F$. tularensis antibody prevalence of $2.0 \%$ (95\% confidence interval: 1.1-3.5) on population level. The distribution of EIU values in our study and control samples is shown in Figure 5 ; the positive control sera showed EIU values between 64.3 and 93.0 .

Five participants had an EIU value $>50$ in addition to a typical LPS band pattern in the Western Blot (Figure 6). One of them reported being hospitalised because of tularaemia during the period from 1995 to 2000 (precise time and duration of hospitalisation not available). 


\section{FIGURE 2}

Number of laboratory-confirmed tularaemia cases and timing of vole population peaks, by district, Finland, 1995-2013 $((\mathrm{n}=3,011)$

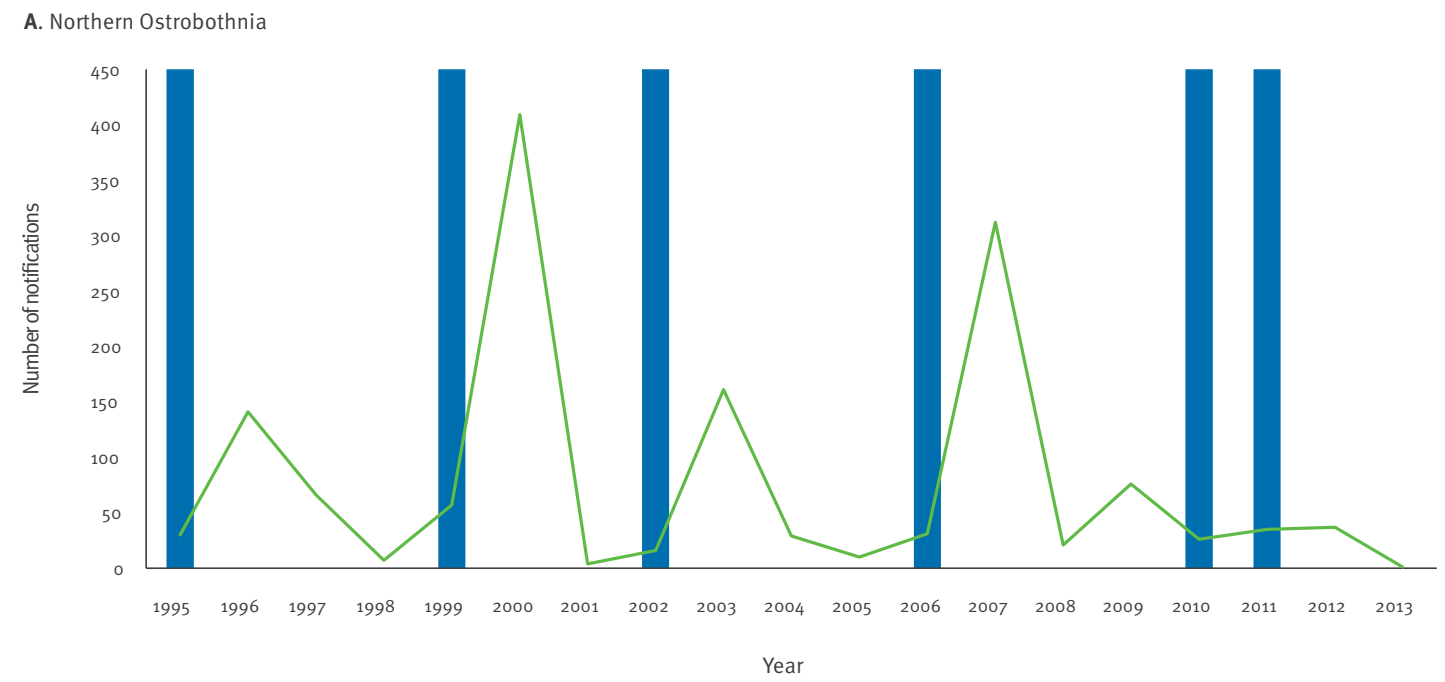

B. Southern Ostrobothnia

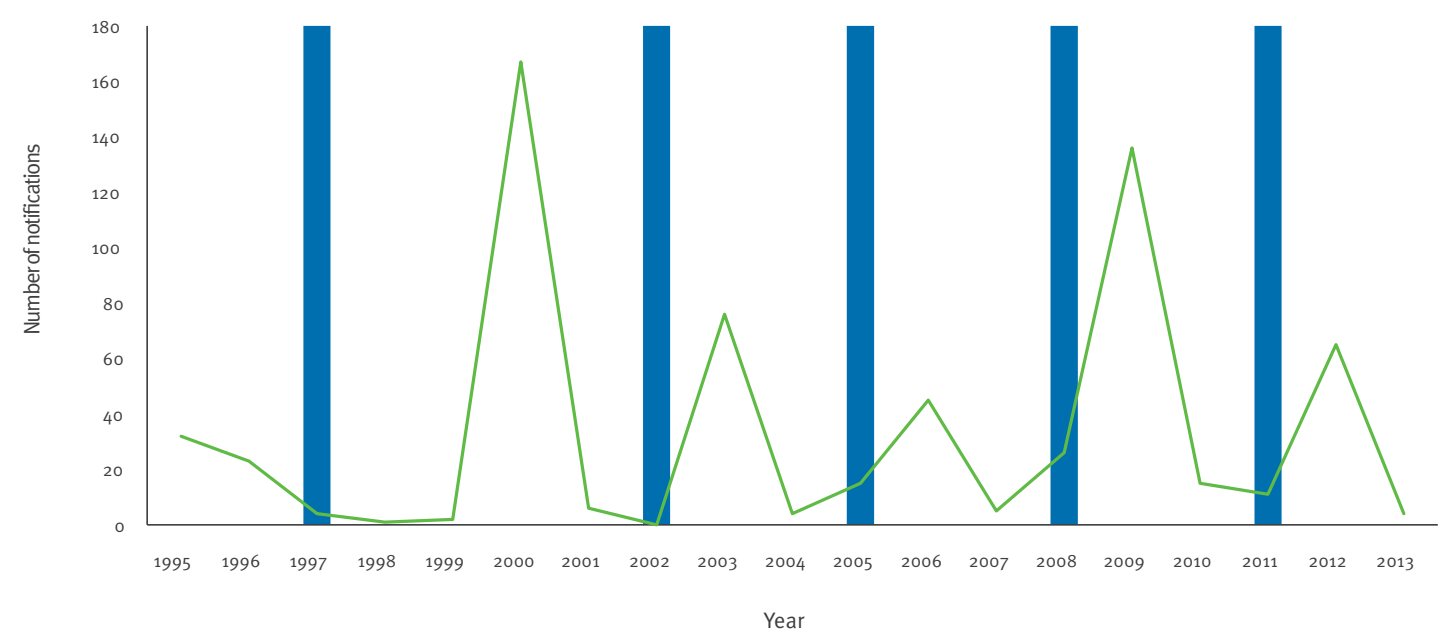

C. Central Finland

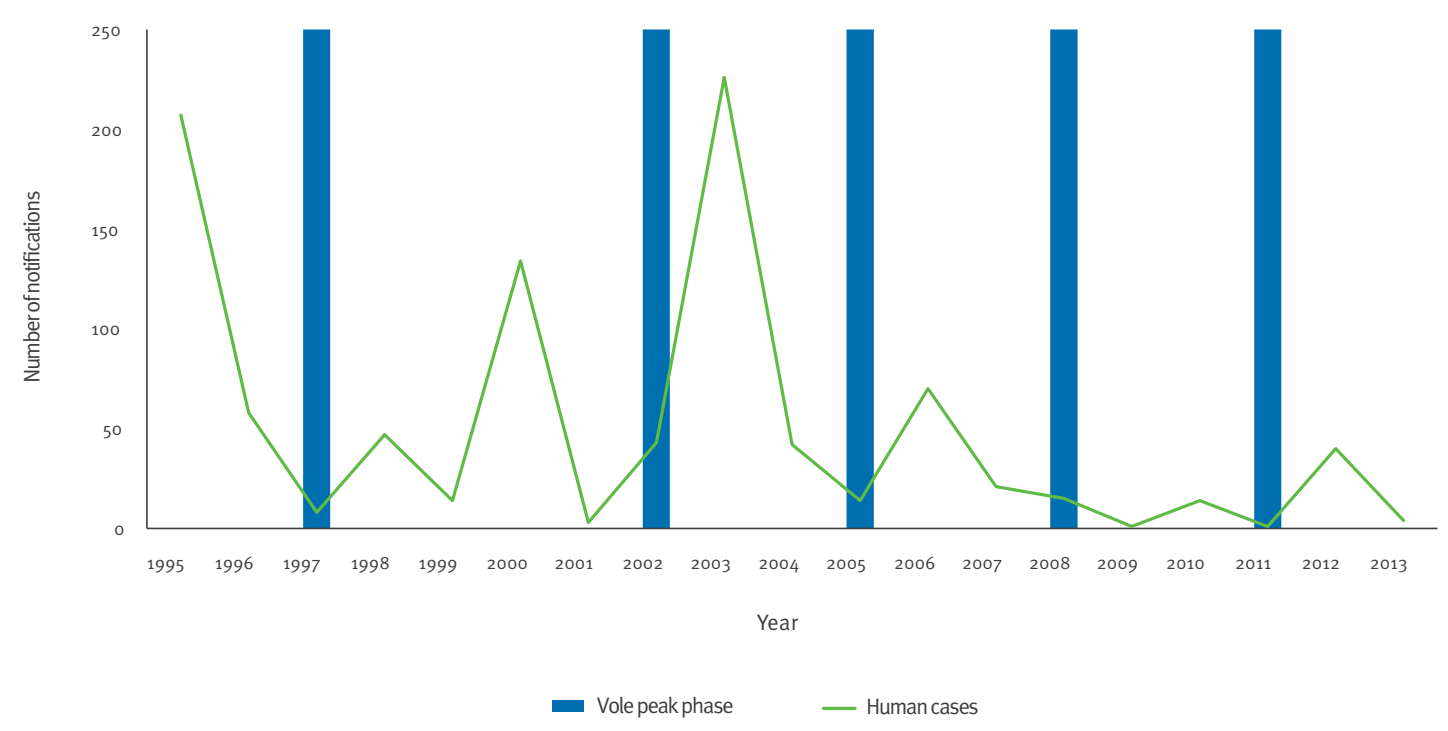

B and C: The year 1999 was not a typical wide-spread peak year, but showed patchy local peaks. For details see text. 


\section{FIGURE 3}

Cumulative number of laboratory-confirmed tularaemia cases by month, Finland, 1995-2013 ( $\mathrm{n}=5,086)$

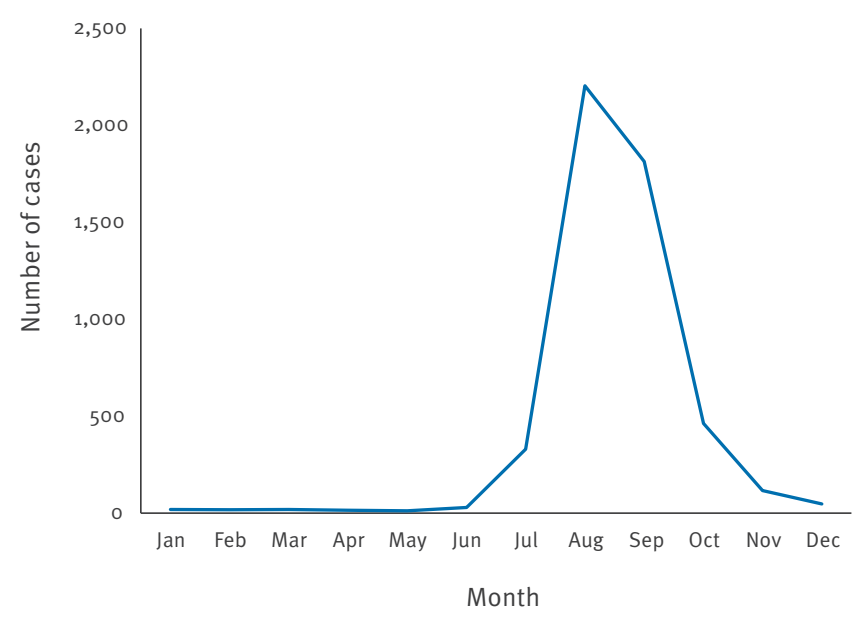

Geographically, the seroprevalence was highest in Northern Ostrobothnia (Figure 7).

No significant differences in age or sex distribution were found between the seropositive and seronegative group. The mean age of seropositive persons in our study was 55 years and $50 \%$ of them were males. No single risk factor was significantly associated with seropositivity. F. tularensis seropositivity in general was higher in persons with lower educational level (likelihood ratio: 0.048), but no single occupation was related to seropositivity. The ratio of notified vs total (estimated based on the observed seroprevalence) $F$. tularensis infections was $1 / 10.5$.

\section{Vole cycles and their association with human tularaemia}

The temporal occurrence of vole peak years clearly predicted human tularaemia outbreaks. Outbreaks mostly occurred during the years immediately after the vole peak years, i.e. in decline years (Figure 2). The tularaemia incidence in vole decline years was on average ca six times higher than in rodent increase years (Table). In 10 of the 20 hospital districts, the vole decline years had a significantly higher tularaemia incidence (incidence rate ratio >1) than the non-decline years. In the remaining districts, tularaemia is rare and the impact of vole cycles could not be observed (the regression model could not be fitted to those particular hospital districts).

\section{Discussion}

The epidemiology of tularaemia in Finland is characterised by recurrent regional and seasonal outbreaks occurring in short cycles of typically three to four years $[3,21]$. In the long term, the incidence is highest in Northern Ostrobothnia as shown also in the current study. Outbreaks involving hundreds of cases occur every three to five years in some areas such as Northern and Southern Ostrobothnia and Central
Finland [3]. In other areas, outbreaks of this magnitude are rare. The majority of cases are reported in August and September, during or right after the late summer mosquito season. It has been shown that the $F$. tularensis carriage rate in mosquitoes in Sweden increases with declining mosquito populations in late summer and early autumn [22], which may explain the high number of notifications in August and September. Also other important mosquito-transmitted diseases in Finland (such as Pogosta disease caused by Sindbis virus) are transmitted particularly by the late summer mosquito species [23].

On the other hand, there is generally a time lag of several weeks between onset of symptoms and laboratory confirmation of tularaemia [3]. Presumably, most cases notified in August and September acquired the infection some weeks earlier. In our serological survey, we found an overall $F$. tularensis antibody prevalence of $2 \%$ on population level after adjustment with survey weights (1.5\% among our study participants). Seroprevalence was highest in Northern Ostrobothnia, which is in line with the number of notifications to the NIDR. The observed seroprevalence was comparable to results from Germany where seroprevalences up to $2.3 \%$ have been found $[24,25]$. In Martha's Vineyard, Massachusetts, where only landscapers were tested, 9.1\% of the studied population was seropositive for F. tularensis [10]. In rural Azerbaijan [26] and Iran [27], seroprevalences significantly higher than in our study were found. In those studies, rodent exposure [26] and hunting [27] were shown to clearly increase the risk of tularaemia. These are well known risk factors for tularaemia.

It was surprising that the $F$. tularensis antibody prevalence was so low in Finland the European Union Member State with the highest reported tularaemia incidence [21,24]. On the other hand, low incidence but relatively high seroprevalence in other countries probably indicates underdiagnosing. This could be explained by the different clinical picture: in Finland, tularaemia is mainly mosquito-borne and manifests as the ulceroglandular form which is easy to diagnose based on the typical symptoms. In central and southern Europe however, the most common is the typhoidal form which is very difficult to diagnose because similar symptoms can have other causes and because the awareness among clinicians is low. Also in Finland, a certain proportion of infections are not notified, which is not surprising, especially when taking into account the challenging laboratory diagnosis of tularaemia. General practitioners in endemic areas probably often treat the disease based on a clinical diagnosis only and diagnostic laboratory tests are not requested. Some patients may also recover after an influenza-like febrile illness without seeking medical attention [10]. On the other hand, the low prevalence of antibodies against $F$. tularensis indicates that tularaemia infection is not very common and is in most cases associated with distinct acute clinical symptoms $[2,16]$. Based on the 


\section{FIGURE 4}

Incidence of laboratory-confirmed Francisella tularensis infections reported to the National Infectious Disease Register, by healthcare district, Finland 1995-2000

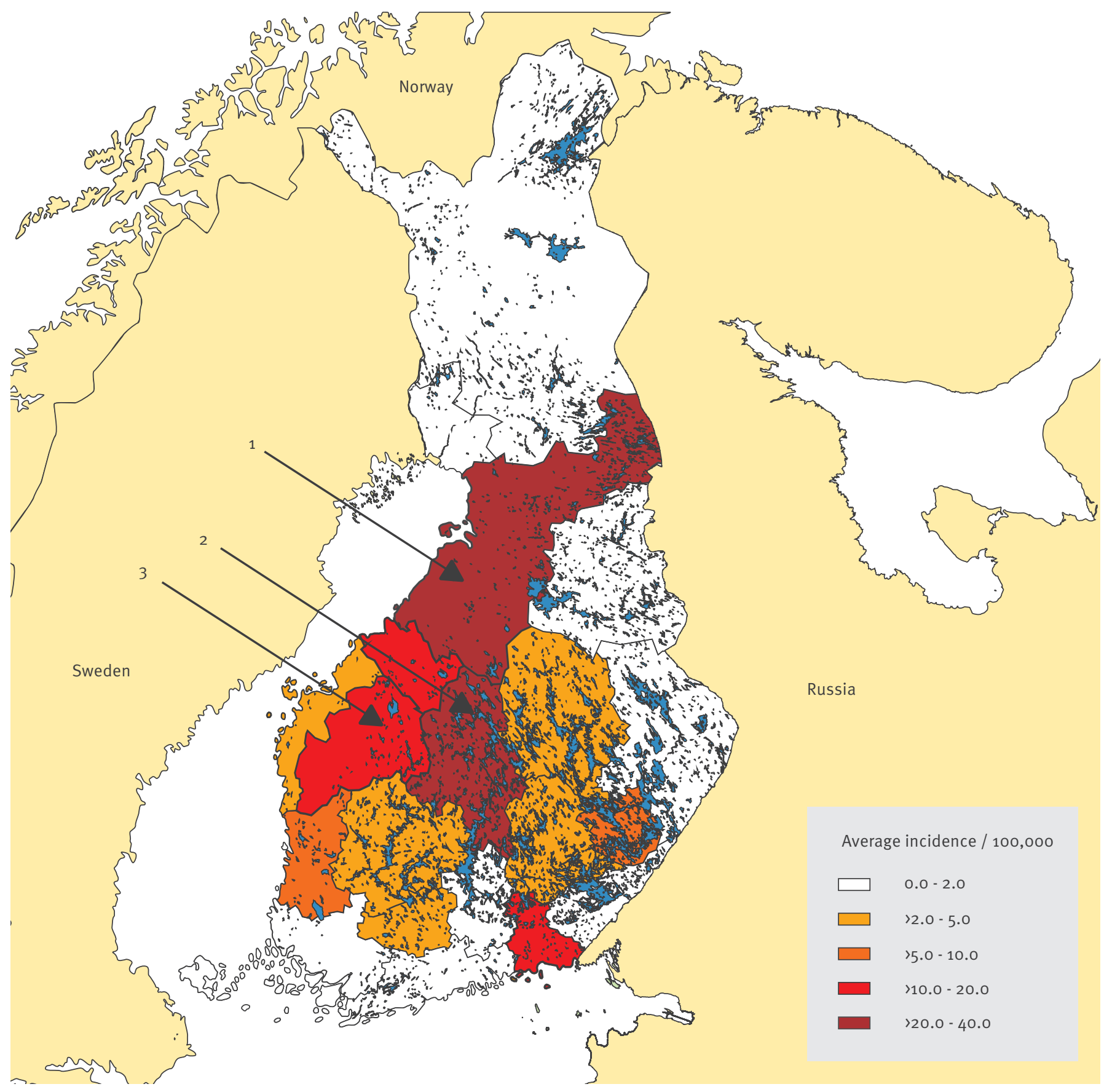

Incidences per 100,000 population.

Healthcare districts: 1 . Northern Ostrobothnia; 2. Central Finland; 3. Southern Ostrobothnia.

notifications and serocoprevalence, we estimate that ca one in $10(9.5 \%) F$. tularensis infections are notified.

We have shown a correlation between vole population dynamics and human tularaemia outbreaks. Human tularaemia outbreaks typically occur during the vole decline phase a year after the vole population peak. In 2000, human tularaemia outbreaks occurred throughout Finland, including Southern Ostrobothnia and
Central Finland, although characteristics of a widespread vole peak in the preceding year were only met in the northern part of the country. Vole peaks occurred in a patchy fashion in 1999, and particularly in Southern Ostrobothnia, our long-term monitoring sites representing the large hospital districts may not have coincided with the localised vole peak areas [28]. We did not include 1999 as a peak year in our statistics, but 


\section{FIGURE 5}

Distribution of ELISA results, tularaemia seroprevalence study, Finland, 2000-01 ( $\mathrm{n}=1,045)$

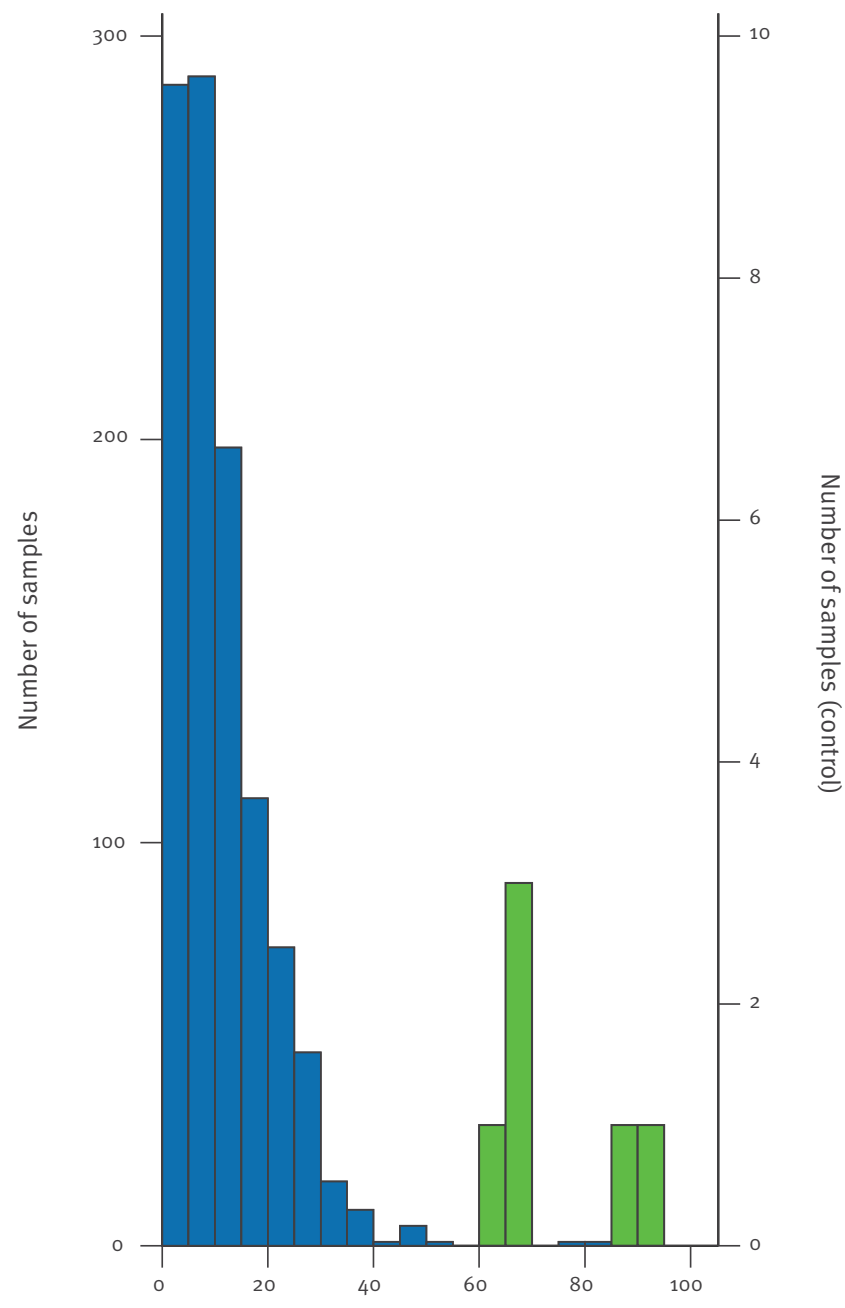

ELISA, EIU

ELISA: enzyme-linked immunosorbent assay; EIU: enzyme-immunosorbent units.

Blue bars: study samples; green bars: positive control samples.

the association between the cyclic phase and human tularaemia was nevertheless significant.

We have previously shown that voles can serve as amplification hosts for F. tularensis [29]. Large vole populations allow the bacteria to replicate intensively. During a peak phase, live rodents can shed the bacteria into the environment, and in the decline phase, infected dead rodents release large amounts of $F$. tularensis into the environment, including breeding sites of mosquitoes [29]. Mosquito larvae can take up the bacteria [22] and once they become adults, spread the bacteria to susceptible hosts that act as local amplifiers. This provides a likely explanation for the suggested association between vole cycles and human tularaemia incidence [29]. However, the variation in the magnitude and the locality of human tularaemia outbreaks warrant further analyses. High vole density is

\section{FIGURE 6}

Western blot of representative positive and negative sera, tularaemia seroprevalence study, Finland, 2000-01

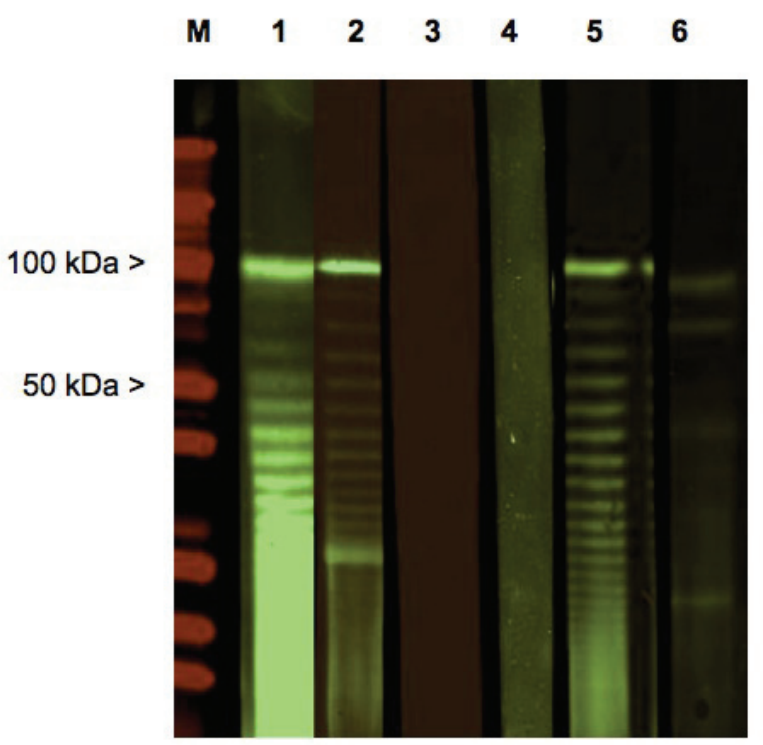

Lanes 1, 2 and 5: samples considered Fransicella tularensis antibody-positive according to a typical ladder pattern; lanes 3 and 4: negative samples from the serosurvey panel; lane 6: a sample considered as an unspecific reaction. M: size marker.

probably one, but not the only prerequisite for tularaemia outbreaks. The local ecological factors crucial for disease outbreaks are still not known very well. It has been shown that the presence of certain aquatic amoebae enhances the multiplication of $F$. tularensis and that its infection process in amoebae resembles that in macrophages [30]. Possibly vole carcasses contaminate natural waters, amoebae support the local persistence of $F$. tularensis in these waters, mosquito larvae feed on these protozoa and thus get infected. Weather conditions influence the amount of mosquitoes, which impacts on the transmission to humans and thus the amplitude of the outbreak [31].

\section{Conclusion}

In summary, human tularaemia in Finland is focal, and most of the cases occur in a few districts. This warrants landscape ecological analyses [8,32]. The answer may not be simple because the endemic provinces differ considerably in topography. The seasonality of tularaemia occurrence strongly indicates a major role of mosquitoes in disease spread. The multiannual cyclic pattern of the epidemics is associated with vole density cycles, with vole peak years preceding epidemic years. The interactions between voles, mosquitoes and $F$. tularensis need still further studies, as well as the discrepancy between the relatively low seroprevalence and considerable incidence of tularaemia. 
TABLE

Incidence of tularaemia in different hospital districts and its relation to rodent cycles, Finland, 1995-2013

\begin{tabular}{|c|c|c|c|c|c|c|c|c|}
\hline Hospital district & Vole cycle phase & Cases (n) & Population & Incidence & IRR & \multicolumn{2}{|c|}{$95 \%$ Wald $\mathrm{Cl}$ for IRR } & $p$ value \\
\hline \multirow{2}{*}{ Southern Karelia } & non decline years & 6 & $1,417,302$ & 0.42 & 3.14 & 0.98 & 10.01 & 0.05 \\
\hline & decline years & 12 & 902,885 & 1.33 & & & & \\
\hline \multirow{2}{*}{ Southern Ostrobothnia } & non decline years & 111 & $2,164,737$ & 5.13 & 7.37 & 2.83 & 19.22 & $<0.001$ \\
\hline & decline years & 522 & $1,381,053$ & 37.80 & & & & \\
\hline \multirow{2}{*}{ Southern Savo } & non decline years & 15 & $1,149,203$ & 1.31 & 1.46 & 0.47 & 4.53 & 0.51 \\
\hline & decline years & 14 & 732,287 & 1.91 & & & & \\
\hline \multirow{2}{*}{ Helsinki and Uusimaa } & non decline years & 100 & $15,789,947$ & 0.63 & 4.29 & 2.15 & 8.55 & $<0.001$ \\
\hline & decline years & 272 & $10,020,284$ & 2.71 & & & & \\
\hline \multirow{2}{*}{ Eastern Savo } & non decline years & 2 & 702,300 & 0.28 & 18.08 & 0.61 & 536.11 & 0.09 \\
\hline & decline years & 23 & 446,602 & 5.15 & & & & \\
\hline \multirow{2}{*}{ Kainuu } & non decline years & 3 & $1,245,547$ & 0.24 & 3.28 & 0.63 & 17.01 & 0.16 \\
\hline & decline years & 2 & 253,206 & 0.79 & & & & \\
\hline \multirow{2}{*}{ Kanta-Häme } & non decline years & 9 & $1,856,789$ & 0.48 & 5.07 & 1.90 & 13.49 & $<0.001$ \\
\hline & decline years & 29 & $1,181,058$ & 2.46 & & & & \\
\hline \multirow{2}{*}{ Central Ostrobothnia } & non decline years & 204 & 931,902 & 21.89 & 1.22 & 0.16 & 9.36 & 0.85 \\
\hline & decline years & 124 & 462,955 & 26.78 & & & & \\
\hline \multirow{2}{*}{ Central Finland } & non decline years & 233 & $2,934,836$ & 7.94 & 4.89 & 1.95 & 12.26 & $<0.001$ \\
\hline & decline years & 725 & $1,865,762$ & 38.86 & & & & \\
\hline \multirow{2}{*}{ Kymenlaakso } & non decline years & 78 & $1,991,154$ & 3.92 & 2.58 & 0.86 & 7.69 & 0.09 \\
\hline & decline years & 128 & $1,267,302$ & 10.10 & & & & \\
\hline \multirow{2}{*}{ Lapland } & non decline years & 15 & $2,074,033$ & 0.72 & 2.34 & 0.41 & 13.32 & 0.34 \\
\hline & decline years & 2 & 118,189 & 1.69 & & & & \\
\hline \multirow{2}{*}{ Western Ostrobothnia } & non decline years & 20 & $1,149,854$ & 1.74 & 0.00 & 0.00 & 0.00 & $<0.001$ \\
\hline & decline years & 0 & 64,655 & 0.00 & & & & \\
\hline \multirow{2}{*}{ Päijänne Tavastia } & non decline years & 17 & $2,293,263$ & 0.74 & 2.03 & 0.48 & 8.63 & 0.34 \\
\hline & decline years & 22 & $1,459,719$ & 1.51 & & & & \\
\hline \multirow{2}{*}{ Pirkanmaa } & non decline years & 104 & $5,098,236$ & 2.04 & 3.60 & 0.88 & 14.84 & 0.08 \\
\hline & decline years & 238 & $3,237,195$ & 7.35 & & & & \\
\hline \multirow{2}{*}{ Northern Karelia } & non decline years & 11 & $1,885,503$ & 0.58 & 0.71 & 0.19 & 2.70 & 0.62 \\
\hline & decline years & 5 & $1,203,895$ & 0.42 & & & & \\
\hline \multirow{2}{*}{ Northern Ostrobothnia } & non decline years & 408 & $4,931,836$ & 8.27 & 6.75 & 3.31 & 13.75 & $<0.001$ \\
\hline & decline years & 1,060 & $1,898,901$ & 55.82 & & & & \\
\hline \multirow{2}{*}{ Northern Savo } & non decline years & 20 & $2,764,993$ & 0.72 & 4.95 & 2.04 & 12.00 & $<0.001$ \\
\hline & decline years & 63 & $1,760,755$ & 3.58 & & & & \\
\hline \multirow{2}{*}{ Satakunta } & non decline years & 54 & $2,519,350$ & 2.14 & 10.77 & 2.75 & 42.20 & $<0.001$ \\
\hline & decline years & 371 & $1,607,604$ & 23.08 & & & & \\
\hline \multirow{2}{*}{ Vaasa } & non decline years & 29 & $1,996,883$ & 1.45 & 7.58 & 2.74 & 20.99 & $<0.001$ \\
\hline & decline years & 110 & 999,243 & 11.01 & & & & \\
\hline \multirow{2}{*}{ South-west Finland } & non decline years & 11 & $5,038,620$ & 0.22 & 6.87 & 2.63 & 17.95 & $<0.001$ \\
\hline & decline years & 48 & $3,201,242$ & 1.50 & & & & \\
\hline \multirow{2}{*}{ Whole country } & non decline years & 1,450 & $59,936,288$ & 2.42 & $4 \cdot 57$ & $4 \cdot 31$ & 4.86 & $<0.001$ \\
\hline & decline years & 3,770 & $34,064,792$ & 11.07 & & & & \\
\hline
\end{tabular}

$\mathrm{Cl}$ : confidence interval; IRR: incidence rate ratio. 


\section{FIGURE 7}

Estimated seroprevalence (prevalence of Western blot positive samples), by healthcare district, tularaemia seroprevalence study, Finland, 2000-01 ( $\mathrm{n}=1,045)$

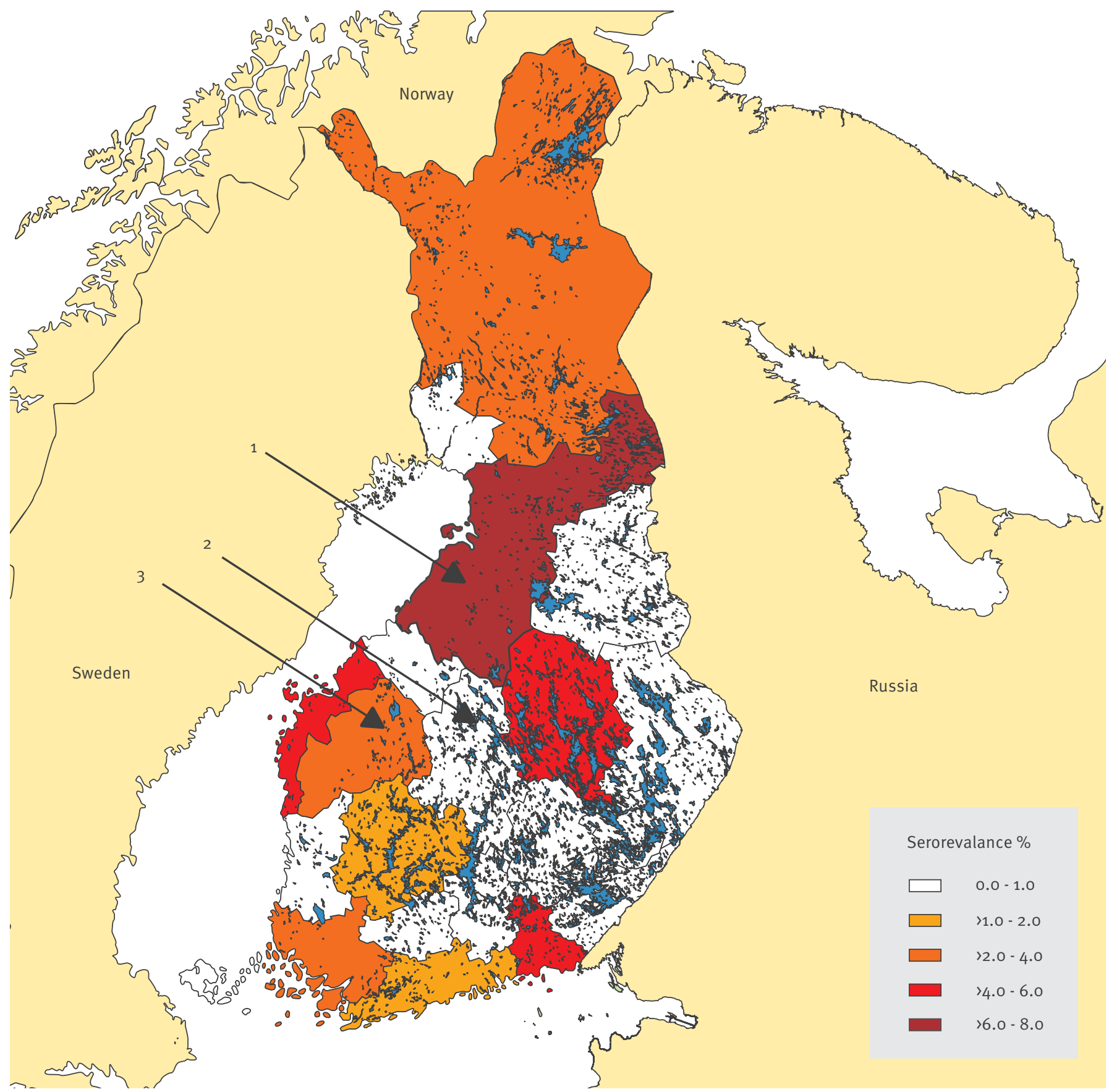

Healthcare districts: 1. Northern Ostrobothnia; 2. Central Finland; 3. Southern Ostrobothnia.

${ }^{*}$ Note

This designation is without prejudice to positions on status, and is in line with United Nations Security Council Resolution $1244 / 99$ and the International Court of Justice Opinion on the Kosovo declaration of independence.

\section{Acknowledgements}

This study was partially funded by the Hospital district of Helsinki and Uusimaa (EVO THY20113 to OV) and the Paulo Foundation (grant to HRo in 2013). Anna Karvonen is thanked for performing the ELISA analyses. The rodent monitoring has been partially supported by the European programs GOCE-CT-2003-010284 EDEN and FP7-261504 EDENext, and the paper is catalogued by the EDENext Steering Committee as EDENextooo (http://www.edenext.eu), as well by Kone Foundation (Finland).

\section{Conflict of interest}

None declared. 


\section{Authors' contributions}

Conceived and designed the experiments: HRo, MK, OV. Performed the experiments: $\mathrm{HRo}, \mathrm{HRi}, \mathrm{OH}$. Analysed the data: HRo, JO, JH, MK, HH, OV. Contributed reagents/materials/analysis tools: $\mathrm{OV}, \mathrm{JH}, \mathrm{HH}$. Contributed to the writing of the manuscript: HRo, JH, JO, MK, OV.

\section{References}

1. Oyston PC, Sjostedt A, Titball RW. Tularaemia: bioterrorism defence renews interest in Francisella tularensis. Nat Rev Microbiol. 2004;2(12):967-78. http://dx.doi.org/10.1038/ nrmicr01045 PMID:15550942

2. Dennis DT, Inglesby TV, Henderson DA, Bartlett JG, Ascher MS, Eitzen E, et al. Tularemia as a biological weapon: medical and public health management. JAMA. 2001;285(21):2763-73. http://dx.doi.org/10.1001/jama.285.21.2763 PMID:11386933

3. Rossow H, Ollgren J, Klemets P, Pietarinen I, Saikku J, Pekkanen E, et al. Risk factors for pneumonic and ulceroglandular tularaemia in Finland: A population-based case-control study. Epidemiol Infect. 2014:142(10):2207-16 PMID:24289963

4. Eliasson H, Lindbäck J, Nuorti JP, Arneborn M, Giesecke J, Tegnell A. The 2000 tularemia outbreak: a case-control study of risk factors in disease-endemic and emergent areas, Sweden. Emerg Infect Dis. 2002;8(9):956-60. http://dx.doi. org/10.3201/eido809.020051 PMID:12194773

5. Hauri AM, Hofstetter I, Seibold E, Kaysser P, Eckert J, Neubauer $\mathrm{H}$, et al. Investigating an airborne tularemia outbreak, Germany. Emerg Infect Dis. 2010;16(2):238-43. http://dx.doi. org/10.3201/eid1602.081727 PMID:20113553

6. Allue M, Sopeña CR, Gallardo MT, Mateos L, Vian E, Garcia MJ, et al. Tularaemia outbreak in Castilla y León, Spain, 2007: an update. Euro Surveill. 2008;13(32):18948. PMID:18761900

7. Siret V, Barataud D, Prat M, Vaillant V, Ansart S, Le Coustumier A, et al. An outbreak of airborne tularaemia in France, August 2004. Euro Surveill. 2006;11(2):pii=598. PMID:16525197

8. Svensson K, Bäck E, Eliasson H, Berglund L, Granberg M, Karlsson L, et al. Landscape epidemiology of tularemia outbreaks in Sweden. Emerg Infect Dis. 2009;15(12):1937-47. http://dx.doi.org/10.3201/eid1512.090487 PMID:19961673

9. Sjöstedt A. Tularemia: history, epidemiology, pathogen physiology, and clinical manifestations. Ann N Y Acad Sci. 2007;1105(1):1-29. http://dx.doi.org/10.1196/annals.1409.009 PMID:17395726

10. Feldman KA, Stiles-Enos D, Julian K, Matyas BT, Telford SR 3rd, Chu MC, et al. Tularemia on Martha's Vineyard: seroprevalence and occupational risk. Emerg Infect Dis. 2003;9(3):350-4. http://dx.doi.org/10.3201/eidog03.020462 PMID:12643831

11. Larssen KW, Bergh K, Heier BT, Vold L, Afset JE. All-time high tularaemia incidence in Norway in 2011: report from the national surveillance. Eur J Clin Microbiol Infect Dis. 2014;33(11):1919-26. http://dx.doi.org/10.1007/s10096-0142163-2 PMID:24874046

12. Reintjes R, Dedushaj I, Gjini A, Jorgensen TR, Cotter B, Lieftucht $A$, et al. Tularemia outbreak investigation in Kosovo: case control and environmental studies. Emerg Infect Dis. 2002;8(1):69-73. http://dx.doi.org/10.3201/eido801.010131 PMID:11749751

13. Brantsaeter AB, Krogh T, Radtke A, Nygard K. Tularaemia outbreak in northern Norway. Euro Surveill. 2007;12(3):E070329.2. PMID:17439796

14. Grunow R, Kalaveshi A, Kühn A, Mulliqi-Osmani G, Ramadani N. Surveillance of tularaemia in Kosovo, 2001 to 2010. Euro Surveill. 2012;17(28):pii=20217. PMID:22835441

15. Dahlstrand S, Ringertz O, Zetterberg B. Airborne tularemia in Sweden. Scand J Infect Dis. 1971;3(1):7-16. http://dx.doi. org/10.3109/inf.1971.3.issue-1.02 PMID:5099427

16. Tärnvik A, Chu MC. New approaches to diagnosis and therapy of tularemia. Ann N Y Acad Sci. 2007;1105(1):378-404. http:// dx.doi.org/10.1196/annals.1409.017 PMID:17468229

17. Koskela P, Salminen A. Humoral immunity against Francisella tularensis after natural infection. J Clin Microbiol 1985;22(6):973-9.

18. Heistaro S, editor. Methodology Report. Health 2000 Survey. Helsinki: National Public Health Institute; 2008. Available from: http://urn.fi/URN:NBN:fi-fe201204193320

19. Schmitt P, Splettstösser W, Porsch-Ozcürümez M, Finke E-J, Grunow R. A novel screening ELISA and a confirmatory Western blot useful for diagnosis and epidemiological studies of tularemia. Epidemiol Infect. 2005;133(4):759-66. http://dx.doi. org/10.1017/S0950268805003742 PMID:16050523
20. Korpela K, Delgado M, Henttonen H, Korpimäki E, Koskela E, Ovaskainen 0 , et al. Nonlinear effects of climate on boreal rodent dynamics: mild winters do not negate high-amplitude cycles. Glob Change Biol. 2013;19(3):697-710. http://dx.doi. org/10.1111/gcb.12099 PMID:23504828

21. Rossow H, Sissonen S, Koskela KA, Kinnunen PM, Hemmilä H, Niemimaa J, et al. Detection of Francisella tularensis in voles in Finland. Vector Borne Zoonotic Dis. 2014;14(3):193-8. http:// dx.doi.org/10.1089/vbz.2012.1255 PMID:24575824

22. Thelaus J, Andersson A, Broman T, Bäckman S, Granberg $M$, Karlsson L, et al. Francisella tularensis subspecies holarctica occurs in Swedish mosquitoes, persists through the developmental stages of laboratory-infected mosquitoes and is transmissible during blood feeding. Microb Ecol. 2014;67(1):96-107. http://dx.doi.org/10.1007/s00248-0130285-1 PMID:24057273

23. Kurkela S, Rätti O, Huhtamo E, Uzcátegui NY, Nuorti JP, Laakkonen J, et al. Sindbis virus infection in resident birds, migratory birds, and humans, Finland. Emerg Infect Dis. 2008;14(1):41-7. http://dx.doi.org/10.3201/eid1401.070510 PMID:18258075

24. Splettstoesser WD, Piechotowski I, Buckendahl A, Frangoulidis D, Kaysser P, Kratzer W, et al. Tularemia in Germany: the tip of the iceberg? Epidemiol Infect. 2009;137(5):736-43. http:// dx.doi.org/10.1017/S0950268808001192 PMID:18808726

25. Jenzora A, Jansen A, Ranisch H, Lierz M, Wichmann O, Grunow R. Seroprevalence study of Francisella tularensis among hunters in Germany. FEMS Immunol Med Microbiol. 2008;53(2):183-9. http://dx.doi.org/10.1111/j.1574695X.2008.00408.x PMID:18462387

26. Clark DV, Ismailov A, Seyidova E, Hajiyeva A, Bakhishova $\mathrm{S}$, Hajiyev $\mathrm{H}$, et al. Seroprevalence of tularemia in rural Azerbaijan. Vector Borne Zoonotic Dis. 2012;12(7):558-63. http://dx.doi.org/10.1089/vbz.2010.0081 PMID:22452727

27. Esmaeili S, Gooya MM, Shirzadi MR, Esfandiari B, Amiri FB, Behzadi MY, et al. Seroepidemiological survey of tularemia among different groups in western Iran. Int J Infect Dis. 2014;18:27-31. http://dx.doi.org/10.1016/j.ijid.2013.08.013 PMID:24145011

28. Korpimäki E, Norrdahl K, Huitu O, Klemola T. Predator-induced synchrony in population oscillations of coexisting small mammal species. Proc Biol Sci. 2005;272(1559):193-202.

29. Rossow H, Forbes KM, Tarkka E, Kinnunen PM, Hemmilä H, Huitu 0 , et al. Experimental Infection of voles with Francisella tularensis indicates their amplification role in tularemia outbreaks. PLoS ONE. 2014;9(10):e108864. http://dx.doi. org/10.1371/journal.pone.0108864 PMID:25271640

30. Abd H, Johansson T, Golovliov I, Sandström G, Forsman M. Survival and growth of Francisella tularensis in Acanthamoeba castellanii. Appl Environ Microbiol. 2003;69(1):600-6. http:// dx.doi.org/10.1128/AEM.69.1.600-606.2003 PMID:12514047

31. Rydén P, Björk R, Schäfer ML, Lundström JO, Petersén $B$, Lindblom A, et al. Outbreaks of tularemia in a boreal forest region depends on mosquito prevalence. J Infect Dis. 2012;205(2):297-304. http://dx.doi.org/10.1093/infdis/jir732 PMID:22124130

32. Desvars A, Furberg $M$, Hjertqvist $M$, Vidman L, Sjöstedt A, Rydén $P$, et al. Epidemiology and ecology of tularemia in Sweden, 1984-2012. Emerg Infect Dis. 2015;21(1):32-9. http:// dx.doi.org/10.3201/eid2101.140916 PMID:25529978 